\title{
Analysis and modelling of tree succession on a recent rockslide deposit
}

\author{
Liesbet Van der Burght • Markus Stoffel • \\ Christof Bigler
}

Received: 29 August 2011/Accepted: 7 November 2011/Published online: 19 November 2011

(C) Springer Science+Business Media B.V. 2011

\begin{abstract}
Dendroecological methods were combined with vegetation and soil mapping to study recolonisation of European larch (Larix decidua), silver birch (Betula pendula) and Norway spruce (Picea abies) on a recently formed rockslide cone (deposit of $30 \times 10^{6} \mathrm{~m}^{3}$ ) in the Valais Alps (Switzerland). Tree density and tree height were predicted with regression models that we derived using an information-theoretic model selection approach. Results demonstrate that the deposits of the 1991 rockslide have been colonised relatively rapidly with larch (ecesis time 2 years), birch (5 years) and spruce (2 years). Most of the colonisation occurred 5-11 years following the rockslide. Clast size was the primary factor driving tree colonisation with the highest tree densities found on plots with mainly smaller $(<30 \mathrm{~cm})$ clast sizes. Tree height was affected by a combination of
\end{abstract}

L. Van der Burght · M. Stoffel ( $\square)$

Laboratory of Dendrogeomorphology,

Institute of Geological Sciences, University of Berne,

Berne, Switzerland

e-mail: markus.stoffel@dendrolab.ch

M. Stoffel

Chair for Climatic Change and Climate Impacts, Institute for Environmental Sciences,

University of Geneva, Geneva, Switzerland

C. Bigler

Forest Ecology, Institute of Terrestrial Ecosystems, Department of Environmental Sciences, ETH Zurich,

Zurich, Switzerland different influences, with tree age and tree density showing the most obvious effects. This study demonstrates how dendroecological methods allow reconstruction of spatio-temporal patterns of tree succession on rockslides, which may ultimately facilitate a more accurate dating of similar landforms of unknown age.

Keywords Rockslide - Dendroecology · Primary succession - Ecesis - Regeneration - Betula pendula . Larix decidua $\cdot$ Picea abies

\section{Introduction}

Alpine regions are characterised by rugged topography and geomorphic disturbances such as rockslides, landslides, avalanches, glaciations or floods (Porter and Orombelli 1980; Lewis and Smith 2004; Shroder et al. 2012). Recently created surfaces are colonised by vegetation passing through different successional phases. These phases are initially controlled by factors such as seed dispersal (e.g. distance to seed source, wind direction, timing of seed release), weather conditions, edaphic factors and erosion (Piotti et al. 2009), before other factors may become of importance such as browsing by ungulates, competition and pathogens (Cunningham et al. 2006).

In the past, several authors have used dendroecological methods to date surfaces created by geomorphic disturbances. However, a recurring problem 
hindering accurate dating of geomorphic disturbances has been the lack of data on ecesis, which is the time interval between surface formation or stabilisation and its colonisation by plants (Desloges and Ryder 1990; McCarthy and Luckman 1993). Ecesis is species specific and influenced by site climate (Pierson 2007). Previous studies reported on ecesis values and colonisation characteristics for deglaciated flood plains or moraines (Bleuler 1986; Burga 1999; Garbarino et al. 2010; Masiokas et al. 2010; McCarthy and Luckman 1993), but only a very limited number of past studies have focussed on the colonisation of surfaces created by large-scale gravitational mass movements, which were mostly limited to the re-establishment of vegetation on volcanic deposits (del Moral 1999; del Moral and Ellis 2004; Lindig-Cisneros et al. 2006; MunozSalinas et al. 2007; Pierson 2007). Data on tree succession on rockslides or other kinds of talus deposits is, in contrast, almost completely missing (Wilson 1966; Walker et al. 1996).

In this study, we document primary succession of trees and shrubs on the deposits formed by the 'Grossgufer' rockslide near Randa (Valais Alps, Switzerland; Fig. 1). On 18 April 1991, a series of rockslides deposited $20 \times 10^{6} \mathrm{~m}^{3}$ of gneissic rock and debris in the valley floor, followed by another $10 \times 10^{6} \mathrm{~m}^{3}$ on 9 May 1991 (Schindler et al. 1993). Although rockslide events are a recurrent process in high mountain chains such as the Alps (Erismann and Abele 2001), only few contemporary, well-documented examples exist where detailed data on the geomorphic disturbance (Huggel et al. 2010) can be linked with data on tree succession. Therefore, the objective of this study was to gain insights into the spatial and temporal colonisation of a rockslide by European larch (Larix decidua), Norway spruce (Picea abies) and silver birch (Betula pendula) through (1) a detailed analysis of tree regeneration, tree density and tree ages and (2) a quantification of environmental factors controlling tree density and tree height on the rockslide deposit.

\section{Study site description}

The 'Grossgufer' rockslide deposit is located in the

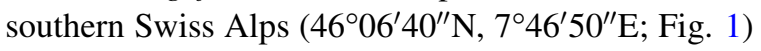
and consists of gneissic and schist lithologies. The rockslide cone has a surface of $\sim 68$ ha and extends

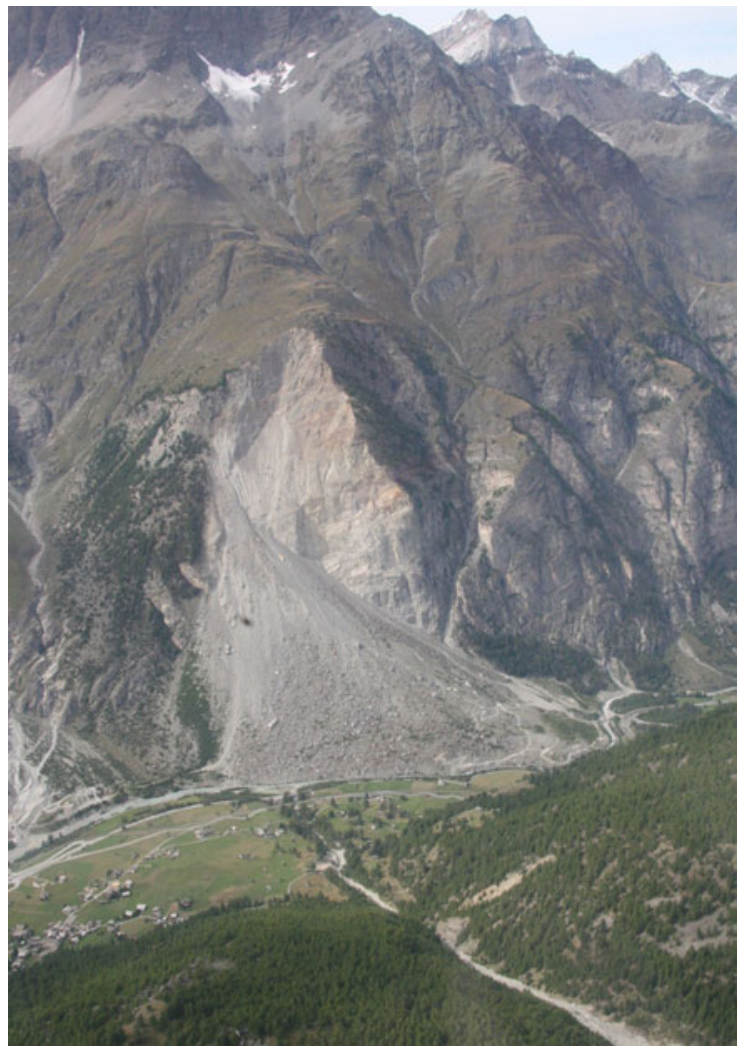

Fig. 1 The 'Grossgufer' rockslide deposit (Randa, Valais Alps, Switzerland) was formed in April and May 1991 by a series of massive rockfalls and rockslides depositing $30 \times 10^{6} \mathrm{~m}^{3}$ of gneissic boulders, rocks and finer sediments

from 1,300 to $1,900 \mathrm{~m}$ a.s.l. The site is characterised by a continental climate with average annual rainfall of $\sim 610 \mathrm{~mm}$ measured at the nearest climate station located in Zermatt $\left(46^{\circ} 01^{\prime} 10^{\prime \prime} \mathrm{N}, 7^{\circ} 44^{\prime} 47^{\prime \prime} \mathrm{E}, 1,618 \mathrm{~m}\right.$ a.s.l.; MeteoSwiss 2011). Winters are relatively short compared to other sites at the same altitude with the rockslide deposit being snow-covered from December to March. Albedo effects of the deposit and the low abundance of vegetation cover have an important influence on local climatic conditions, which tend to be harsher on the cone than elsewhere in the valley. About half of the study site is dominated by large blocks ( $\geq 50 \%$ of clasts with $\varnothing>1 \mathrm{~m}$ ), which create large, shady and relatively moist sites that are preferred environments for several local plant species. Amongst the tree and shrub species observed on the deposit are larch, spruce, birch, green alder (Alnus viridis), European red elder (Sambucus racemosa), purple willow (Salix purpurea), goat willow (Salix caprea), trembling aspen (Populus tremula) and 
sycamore maple (Acer pseudoplatanus). The growing season of trees in the region starts in late-May and ends in early-October (Stoffel et al. 2005). Post-disturbance colonisation by trees and shrubs occurred naturally within the study area from nearby $(<200-500 \mathrm{~m})$ seed sources. In the northern part of the rockslide deposit (Fig. 1) seeding activity has influenced tree regeneration; we therefore excluded this sector and its neighbourhood to avoid anthropogenic signals in the analysis. In addition, broaching and anthropogenic reshaping have deprived the eastern rim of the deposit from its original character, which made sampling in this part of the deposit redundant as well.

Fine-grained debris and silt are most frequent in the northernmost and western segments of the study area; large blocks dominate the south-eastern part (Fig. 1). Between these two rather uniform areas, a transition zone of medium and small blocks is observed. The northern and southern borders of the deposit are funnel shaped and dominated by fine-grained debris and silt. In summary, along a north-south axis, a transition exists from fine-grained debris and silt to large blocks from the outer to the inner regions of the deposit. Along an east-west axis, a less gradual transition from large blocks to fine-grained debris and silt is observed. Soils are scarce on the young deposit and generally characterised by lime deficiency. However, a top layer rich in leaf mould usually exists where vegetation is present.

\section{Methods}

Mapping of substratum and vegetation

The area surveyed is located between 1,380 and 1,500 $\mathrm{m}$ a.s.1. (mean slope gradients: $14-32^{\circ}$ ) and covers 12.3 ha, representing $\sim 18 \%$ of the rockslide deposit. The surface was divided into homogeneous plots of comparable size and plot boundaries defined based on the grain size (GS) distribution of the substratum and on tree density. Spatial data were collected in the field using a Nikon 55DAS laser distometer, compass and clinometer. For a total of 171 plots, 84 were composed of large blocks (GS0 $\geq 50 \%$ of clasts with $\emptyset>1 \mathrm{~m}$; Fig. 2), 40 of medium and small blocks (GS1 $\geq 50 \%$ of clasts with $\varnothing 1-0.3 \mathrm{~m}$ ), and 47 of fine-grained debris and silt (GS2 $\geq 50 \%$ of clasts with $\varnothing<0.3 \mathrm{~m}$ ).
Collection of field data

Fieldwork was conducted in summer 2009 and spring 2010. For 93 of the 171 plots, the number of trees per species was determined, and tree height and age were assessed as described below. The broad range of plots with varying tree composition and density provided sufficient variation to individually compare these with the remaining 78 plots. The relative cover of herbs and shrubs was visually estimated at the plot level.

Tree ages were determined by either (1) counting tree rings at the height of the root collar after destructive sampling of trees or by (2) counting budscale scars on the stem surface (Hoffmann and Schweingruber 2002). The height of larch trees was measured and approximately three trees per plot (i.e. 269 trees within the 93 measured plots) felled. The bud-scale scar method was applied to all larches (i.e. 1,792 trees), except for densely populated plots where trees were visually assigned to several classes of tree height. In addition to the age determination of every larch by counting its bud-scale scars, $10 \%$ of the trees of the respective height class were felled and growth rings were counted to validate the accuracy of the budscale scar approach. For birch, the height of each individual was measured, unless (as in the case of larch) for plots with a high number of trees. A total of 39 birch trees of different height were felled in randomly selected plots to get an estimate of their age. For spruce, tree height was measured as well and approximately $10 \%$ of all specimens were felled per plot (i.e. 45 trees) to determine their age.

Field data were compiled in a database containing information: (1) at the plot level (substratum, total number of trees, number of trees per species, area and tree density); and (2) at the tree level (species, height, bud-scale scar age and tree-ring age). At the plot level topographic variables retrieved from ArcGIS v10, including altitude, slope, aspect and proximity to the nearest forest edge, were added (Table 1).

Modelling tree density and height

To model the number of trees per plot, a generalized linear model assuming a negative binomial distribution (Crawley 2007) was fitted to the birch, larch and spruce populations. The negative binomial distribution allows to model count data with overdispersion, i.e. the variance is greater than the mean (Venables 


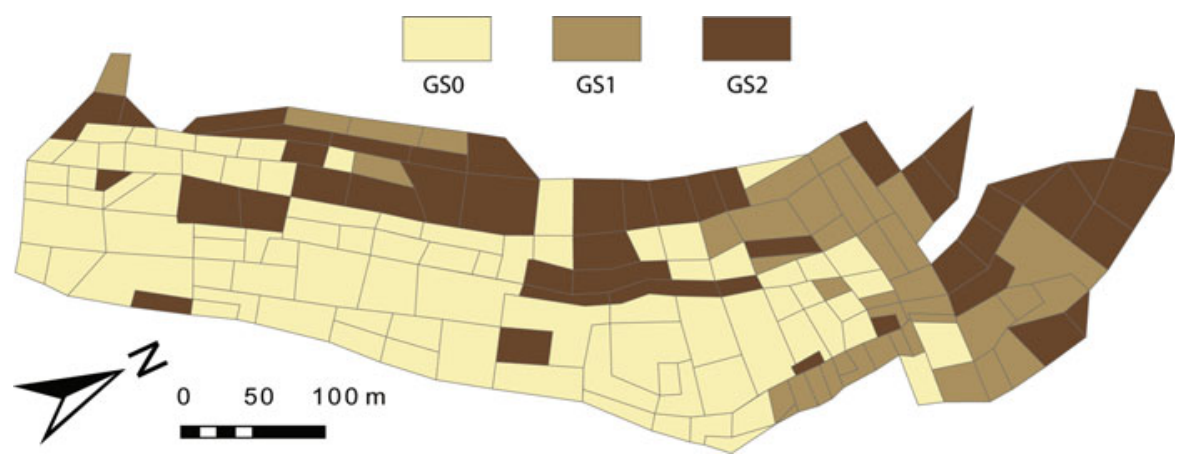

Fig. 2 Grain-size (GS) distribution on the study site located in the lower reaches of the rockslide deposit: GS0 is composed of large blocks $(\geq 50 \%$ of clasts with $\varnothing>1 \mathrm{~m})$, GS1 has predominantly medium and small blocks ( $\geq 50 \%$ of clasts with $\varnothing 1-0.3 \mathrm{~m})$ and GS2 is characterised by fine-grained debris and silt ( $\geq 50 \%$ of clasts with $\varnothing<0.3 \mathrm{~m}$ )

Table 1 Description of variables at the tree and plot level

\begin{tabular}{|c|c|c|}
\hline Variables & Level & Description \\
\hline Species & Tree & $\begin{array}{l}\text { Larix decidua/Betula pendula/Picea abies/Alnus viridis/Sambucus } \\
\text { racemosa/Salix purpurea/Salix caprea/Populus tremula/Acer pseudoplatanus }\end{array}$ \\
\hline Tree height & Tree & Ranging from 0.03 to $7 \mathrm{~m}$ \\
\hline Growth-ring age & Tree & Ranging from 1 to 17 years \\
\hline Bud-scale scar age & Tree & Ranging from 1 to 17 years \\
\hline Substratum (grain size) & Plot & $\begin{array}{l}\text { Large blocks (GS } 0 \text { ): } \geq 50 \% \text { of clasts with } \varnothing>1 \mathrm{~m} \\
\text { Medium and small blocks (GS } 1 \text { ): } \geq 50 \% \text { of clasts with } \varnothing 1-0.3 \mathrm{~m} \\
\text { Fine-grained debris and silt (GS 2): } \geq 50 \% \text { of clasts with } \varnothing<0.3 \mathrm{~m}\end{array}$ \\
\hline Number of trees per species & Plot & Ranging from 0 to 1,526 trees \\
\hline Total number of trees & Plot & Ranging from 0 to 2,877 trees \\
\hline Tree density & Plot & Ranging from 0 to 6,691 trees/ha \\
\hline Area & Plot & Ranging from 57 to $2,356 \mathrm{~m}^{2}$ \\
\hline Altitude & Plot & Ranging from 1382.5 to $1488.9 \mathrm{~m}$ a.s.l. \\
\hline Slope & Plot & Ranging from 14.3 to $32.4^{\circ}$ \\
\hline Distance to nearest forest edge & Plot & Ranging from 217.7 to $512.0 \mathrm{~m}$ \\
\hline Aspect & Plot & $\begin{array}{l}\text { Northeast-facing slopes (NE): } 22-66^{\circ} \\
\text { East-facing slopes (E): } 67-111^{\circ} \\
\text { Southeast-facing slopes (SE): } 112-157^{\circ}\end{array}$ \\
\hline
\end{tabular}

Growth-ring ages were assessed for larch, birch and spruce as described in Collection of field data. Bud-scale scar ages were assessed for larch as described in Collection of field data

and Ripley 2002). The probability density function of the negative binomial distribution is defined for counts $y$ as:

$f(y ; \theta, \mu)=\frac{\Gamma(\theta+y)}{\Gamma(\theta) \times y !} \times \frac{\mu^{y} \theta^{\theta}}{(\mu+\theta)^{\theta+y}}$

where $\Gamma$ is the gamma distribution and $\theta$ is the dispersion parameter. The mean $\mu$ is modelled as: $\log (\mu)=\log (A)+X \beta$

where $\log (A)$ is a vector with the log-transformed plot areas, $X$ is a matrix that contains the predictor variables and $\beta$ is a vector with the regression coefficients. Substratum, altitude, slope, aspect and proximity to the nearest forest edge were set as predictor variables to model the number of trees per plot. For the model selection, we used an information- 
theoretic approach based on the $\mathrm{AIC}_{\mathrm{c}}$ (corrected Akaike Information Criterion) (Burnham and Anderson 2002; Stauffer 2008):

$\mathrm{AIC}_{\mathrm{c}}=-2 \times \log ($ likelihood $)+2 \times p \times \frac{n}{n-p-1}$

where $p$ is the number of parameters used in the model and $n$ is the sample size. We selected a priori nine different models that contained between one and five predictor variables (Table 2); the model with the lowest $\mathrm{AIC}_{\mathrm{c}}$ amongst these candidate models is the best-fitting model. Unlike other model selection approaches such as step-wise model selection, the information-theoretic approach does not emphasize significance testing (Stauffer 2008). Akaike weights $w_{i}$ were then calculated, which are the probability that model $i$ is the best-fitting model amongst the nine models (Burnham and Anderson 2002):

$w_{i}=\frac{\exp \left[-\frac{1}{2} \Delta_{i}\right]}{\sum_{j=1}^{9} \exp \left[-\frac{1}{2} \Delta_{j}\right]}$

where $\Delta_{i}$ designates the difference in $\mathrm{AIC}_{\mathrm{c}}$ between model $i$ and the model with the lowest $\mathrm{AIC}_{\mathrm{c}}$.

To model tree height, log-linear models were fitted to the birch, larch and spruce populations:

$\log ($ height $)=X \beta$

where height is tree height in 2009/2010, $X$ is a matrix with the predictor variables and $\beta$ is a vector that contains the regression coefficients. Age, substratum, tree density, altitude, slope and aspect were used as predictor variables for explaining tree height (Table 3). Similar to the model selection approach for modelling tree density, we selected a priori nine different models (Table 3 ) that we compared based on the $\mathrm{AIC}_{\mathrm{c}}$ (Eq. 3) and Akaike weights (Eq. 4). Since, tree age is expected to be an important variable in predicting tree height, we included the variable age (estimated with tree rings and bud-scale scars for larch and with tree rings for birch and spruce) in any of the models. For birch and spruce, we calculated fixedeffects models (Eq. 5). For larch, we calculated mixed-effects models (Pinheiro and Bates 2000) since several trees per plot were sampled, i.e. the height data were assumed to be dependent within each plot. Thus, to account for plot-to-plot variability, random effects were added for both the intercept and the variable age

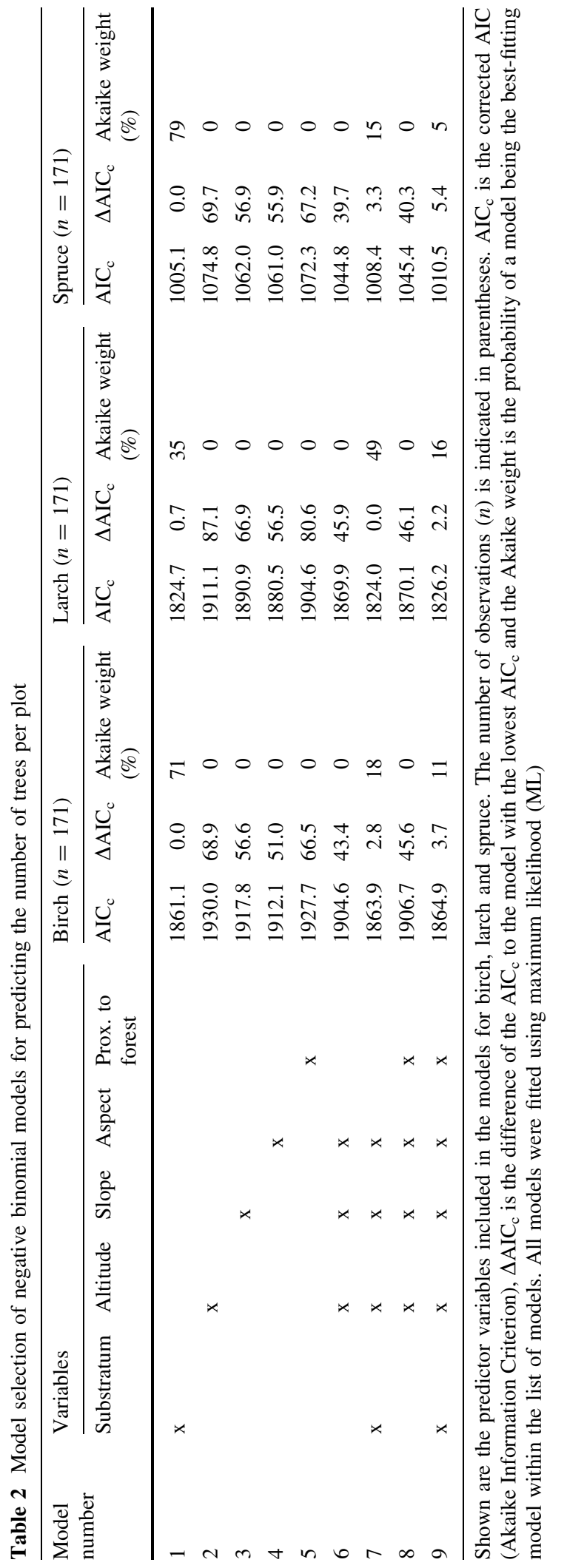




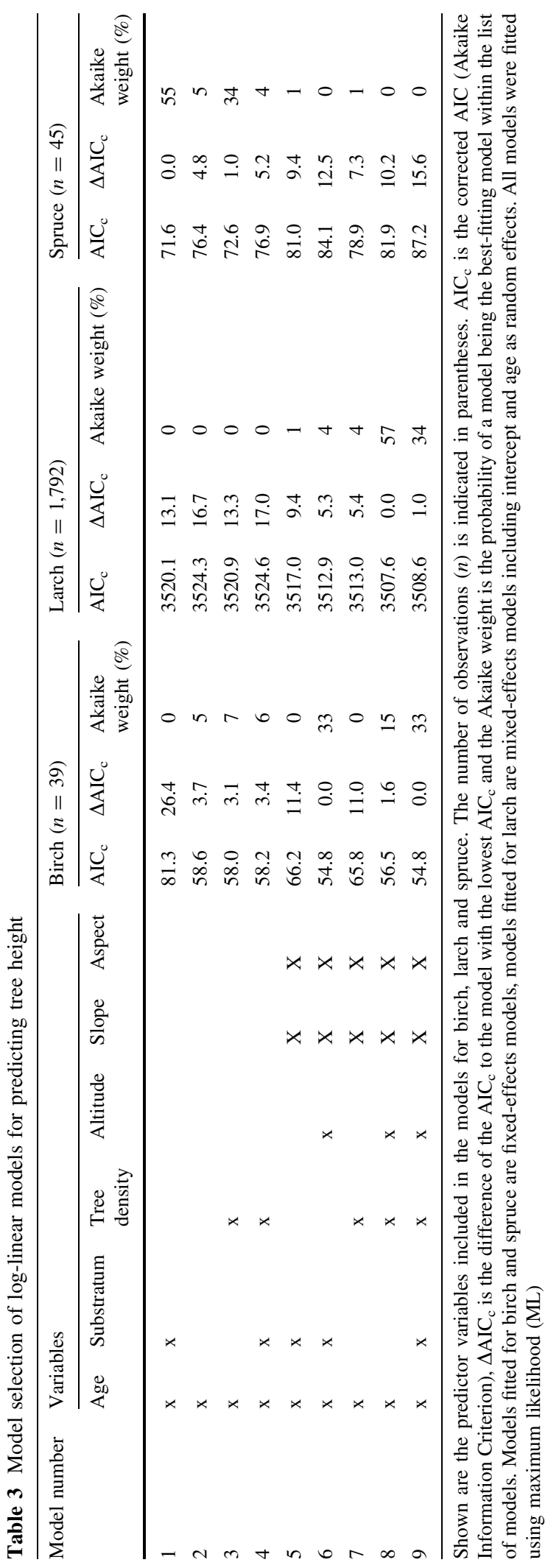

(Eq. 5), which were grouped by plot (Pinheiro and Bates 2000).

Statistical analyses and modelling of the data was conducted with the R software (R Development Core Team, 2010; Version 2.11.1). To fit negative binomial models to the tree density data, we used the function 'glm.nb' in the R package 'MASS' (Venables and Ripley 2002). To predict tree height based on loglinear models, we used the 'gls' function from the $\mathrm{R}$ package 'nlme' for fitting fixed-effects models to the birch and spruce data and the 'Ime' function for fitting mixed-effects models to the larch data (Pinheiro and Bates 2000).

\section{Results}

Tree abundance and density

Larch ( $\sim 45 \%$ of the entire population) and birch ( $\sim 46 \%)$ were clearly the dominant tree species on the rockslide deposit and within the different substratum types (Fig. 3a, b). Differences between their respective abundances seemed to diminish with grain size: from $\sim 10 \%$ for the large blocks (GS0) to $\sim 1 \%$ for the medium and small blocks (GS1) with birch being more abundant in both substratum classes. The smallest difference in abundance of $\sim 0.5 \%$ was observed for fine-grained debris and silt (GS2) with larch being more abundant. Spruce ( $\sim 6 \%$ of the entire population; Fig. 3c) clearly lags behind larch and birch, as do the other species $(\sim 3 \%)$. An average density of 4,062 trees $\mathrm{ha}^{-1}$ was registered with the highest densities estimated on plots of fine-grained debris and silt (Fig. 2). Densities clearly increased with decreasing grain size and were highest for the three most abundant species in the northern and western areas of the deposit (Fig. 3).

Primary succession

The earliest regeneration occurred 2 years after the rockslide in 1993 for larch growing on GS1. The oldest larch growing on GS0 substratum is from 1994 and on GS2 from 1995. An ecesis value of 5 years (1996) was obtained for birch, ecesis values of 2 years were found for spruce.

The development of the larch population was reconstructed by mapping the number of seedlings 
Fig. 3 Stand densities (in $10^{3}$ trees $\mathrm{ha}^{-1}$ ) on the rockslide deposit as observed in 2010 for a larch, b birch and c spruce

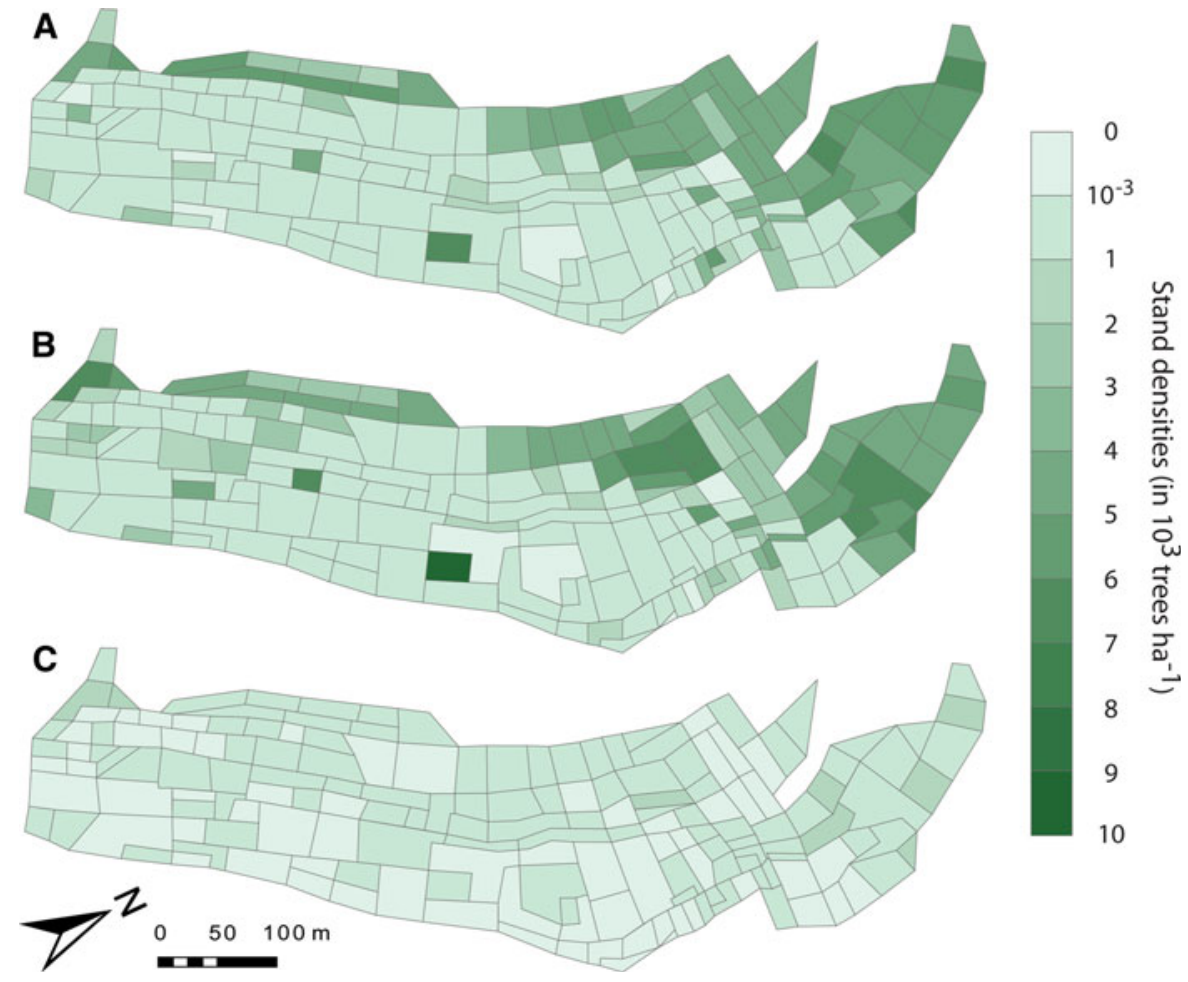

that germinated in a distinct period as a percentage of the current population (Fig. 4). In 1993 and 1994, the surveyed area remained largely void of trees apart from some plots in the north-western segment of the study area, where up to $14 \%$ of the current larch population had germinated (Fig. 4a). Tree expansion was much more intense between 1995 and 1998, when up to $100 \%$ of the current population germinated within some plots. In contrast, a lack of larch germination is still clearly visible in the plots with GS0 between 1995 and 1998 (Fig. 4b). For the period 1999-2002, high colonisation rates were observed in the central part of the study area and plots of any grain size (including GS0) were colonised (Fig. 4c). Colonisation rates diminished again from 2007 to 2010; a maximum of $22 \%$ of the current population established in some plots (Fig. 4e).

Modelling tree density

The model with substratum as the only predictor variable was by far the best-fitting model for predicting tree density for both birch (Akaike weight of 71\%) and spruce (Akaike weight of 79\%) (model 1; Table 2). For both species, the number of trees per plot increased significantly with decreasing grain size (model 1; Table 4). Other models for birch and spruce with Akaike weights between 5 and $18 \%$ additionally included altitude, slope, aspect and proximity to the nearest forest edge (models 7 and 9; Tables 2, 4). For larch there were relatively small differences in terms of Akaike weights between models $7(49 \%)$ and 1 (35\%; Table 2). Similar to larch and birch, both models showed the same effect of substratum on tree density. For model 7, tree densities tended to increase with altitude (Table 4). Similar to larch and birch, tree densities tended to be higher on northeast-facing slopes compared to east-facing slopes.

Modelling tree height

Tree height of birch was equally well fit by models 6 and 9 (Akaike weight 33\%) with model 6 including age, substratum, altitude, slope and aspect, and model 9 additionally including tree density (Table 3). Tree height tended to decrease from GS0 to GS1 to GS2, whereas tree height strongly increased with age and altitude (Table 5). Slope and aspect had only marginal effects on tree height. Increasing tree density tended to decrease tree height (model 9; Table 5). 
Fig. 4 Spatial distribution of freshly sprouted larch seedlings over given time intervals. Changes as compared to the current (2010) larch population are expressed as a percentage: a 1993-1994, b 1995-1998, c 1999-2002, d 2003-2006 and e 2007-2010 seedling number (as \% of current population number)

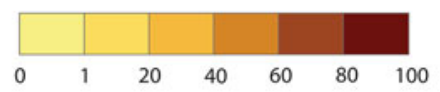

A

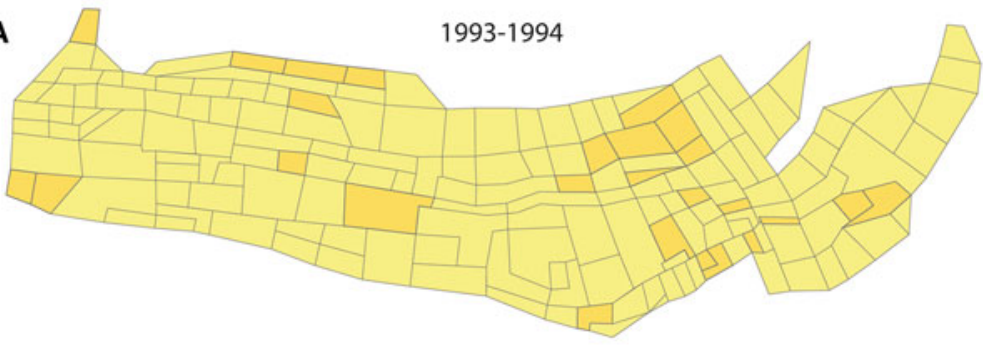

B

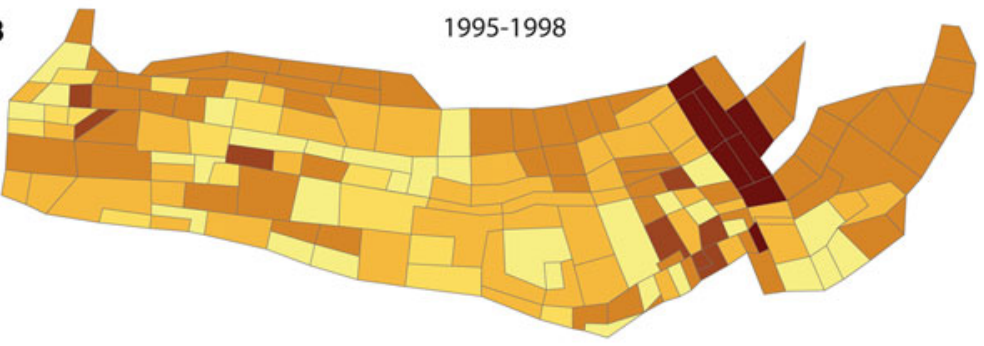

c

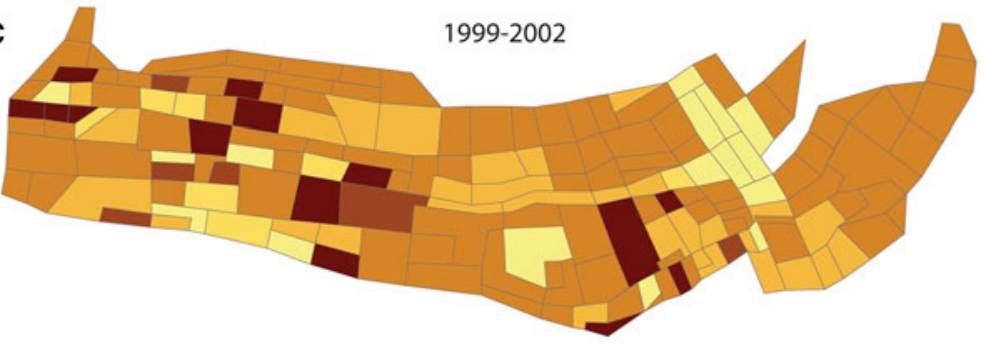

D

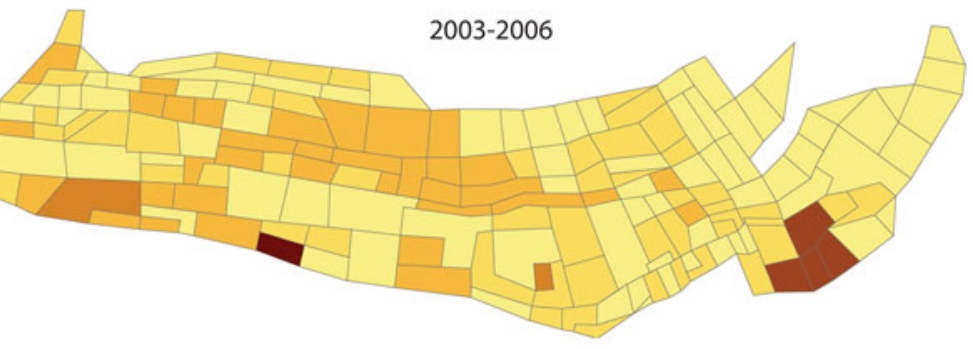

E

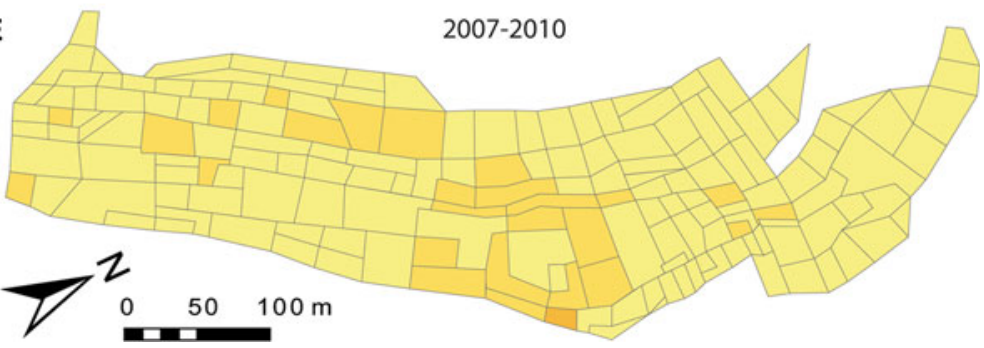


For larch, models 8 and 9 with Akaike weights of 57 and 34\%, respectively, were the best-fitting models with model 9 including all predictor variables and model 8 leaving out only substratum (Table 3). Older trees and trees growing higher up on the deposit and on northeast-facing slopes were growing taller; there were also some positive but marginal effects from substratum and non-significant effects from slope on tree height (Table 5). Tree density had a negative effect on tree height. There was a relatively high plotto-plot variability for the relationship between age and tree height as indicated by the random effects (Table 5).

For spruce, models 1 and 3 were the best-fitting models with Akaike weights of 55 and 34\%, respectively (Table 3). Older trees tended to be taller and tree density had a weak negative effect on tree height (Table 5).

\section{Discussion and conclusions}

This study reports on the analysis and modelling of tree succession on a young (20-year old) $\sim 68$ ha rockslide surface. Our data illustrate that colonisation of the rockslide deposit with trees occurred almost immediately after the event: $\sim 1 \%$ of the current tree population was present on the deposit by 3 years after the event, $\sim 38 \%$ of the population colonised the surface within the first 7 years and $\sim 83 \%$ of the current tree population germinated within 11 years.

The results represent one of the first datasets analysing tree succession on a rockslide deposit, i.e. a surface which is almost bare of any soil and composed of blocky, sandy and silty debris of gneissic origin. A comparison with existing studies on primary succession, which have been conducted in different contexts and on different deposits, is therefore challenging. To a certain degree the ecesis data from our study can be compared with the results of Pierson (2007), who analysed tree colonisation on lahar deposits, where ecesis values ranged from 1 to 14 years. In his study, seed sources were at comparable distances from the study site. However, the deposits on which ecesis was analysed were of different nature (more acid petrology and smaller granulometry) and therefore resulted in much lower albedo. The amount of precipitation differs as well between the two sites, with the Mount St. Helens 


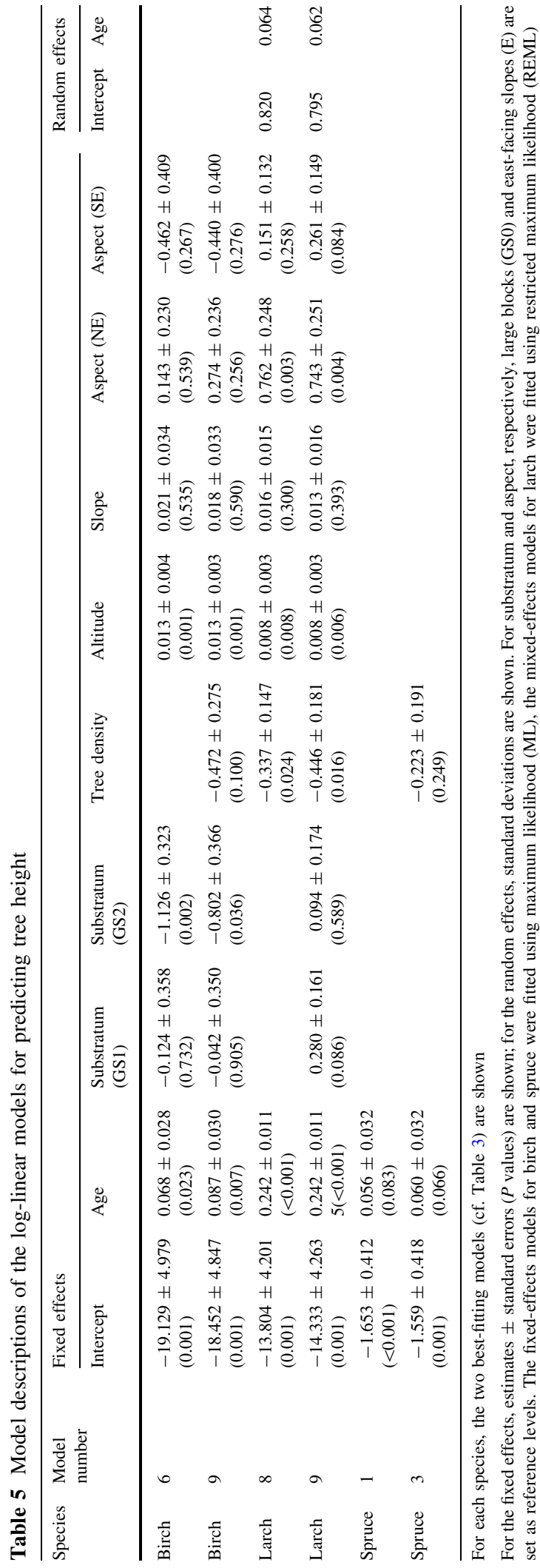

region (Pierson 2007) receiving almost twice as much precipitation as compared to Randa. Much greater differences exist between our data from the rockslide deposit and ecesis in glacier forefields, where colonisation has been studied rather extensively (Bleuler 1986; Burga 1999; Garbarino et al. 2010; McCarthy and Luckman 1993). A comparison of ecesis data from glacier forefields with our data set shows 3-17 times longer lag times, probably reflecting the hampering of tree colonisation in glacier forefields by cool glacial winds, meandering meltwater streams and the scarcity of seed sources.

The large amount of dust produced by the rockslide probably accelerated seedling establishment. Although, the rockslide deposit was not covered with soil sensu stricto, the 400,000-1,000,000 $\mathrm{m}^{3}$ (Schindler et al. 1993) of dust arising from the event provided a fertile fine substrate for seedling establishment. The rockslide deposit was colonised primarily $(\sim 91 \%)$ by the pioneer species larch and birch reflecting their ability to colonise new surfaces (Ellenberg 1988). The number of spruces identified on the deposit $(6 \%)$ was, in contrast, more unusual, since this species tends to occur during secondary successional phases (Ellenberg 1988).

Irrespective of the species, colonisation of the deposit was predominantly determined by the variability of the substratum (Table 2). Tree density of birch, larch and spruce significantly increased from plots with large blocks to plots with fine-grained debris and silt (Table 4). For larch, additional environmental influences including altitude, slope and aspect affected tree density. However, only northeastfacing plots showed a significant increase in tree density. For all three species, this effect may not simply be attributed to the apparent correlation of substratum and aspect (Fig. 2), because any model including substratum as predictor variable achieved a relatively high Akaike weight, which was not the case for models including aspect but not substratum (Table 2). The slight increase of tree density with altitude (model 7, Table 4) should not be attributed to a classical altitudinal effect (i.e. decreasing temperature or increasing precipitation, respectively, with increasing altitude) as the difference in altitude is not large enough between the lower and the upper plots, but most likely reflects changes in soil moisture and nutrient availability or insolation. For all three tree species, distance to the closest forest edge was not of importance for the study site in Randa, probably as a 
result of the light-weight seeds of the three anemochorous tree species and because the closest forest edges were found within $200-500 \mathrm{~m}$ from the plots. Seed dispersal e.g. for Norway spruce has been reported to occur over several $100 \mathrm{~m}$ from the seed source (Piotti et al. 2009).

Important influences on tree height of birch, larch and spruce were tree age and tree density (Table 3). As expected, older trees were taller, whereas tree height decreased with increasing tree density (Table 5). Tree competition seemed to be of importance already less than 20 years following the rockslide, and more so for the shade-intolerant birch and larch than for the intermediate shade-tolerant spruce. For the two pioneer species birch and larch, substratum, altitude, slope, and aspect turned out to be further variables that partially determine tree height. Tree height of birch was reduced on plots with fine-grained debris and silt, i.e. birches in plots with large blocks tended to be larger maybe as a result of the protective effect of the rocks against snow movements. Similar to the effect of altitude on tree density, the significant effect of altitude on tree height might be due to some unmeasured variables that are confounded with altitude such as soil moisture. For larch, northeast-facing slopes seem to be more beneficial for height growth than east-facing slopes (Table 5). Because larch established earlier on northeast-facing plots than on east-facing plots (results not shown), these trees might have had a competitive advantage compared to trees on adjacent plots.

By providing detailed recolonization data for larch and by identifying important environmental influences that affect tree density and the development of tree height for larch, birch and spruce, we increase the general understanding of early tree succession processes on rockslide deposits. Future studies on ecesis and landform dating may benefit from our findings, which indicate what processes drive ecesis times and early successional phases in similar settings. Our results demonstrate how dendroecological methods allow reconstructing spatio-temporal patterns of tree succession on a rockslide, which may ultimately facilitate a more accurate dating of rockslide deposits and similar landforms of unknown age.

Acknowledgments This study has benefited from field assistance of Oliver Fux. We acknowledge the local forester Leo Jörger for the sampling permit. We would like to thank Associate Editor Chris Lusk and two reviewers for providing useful comments on the manuscript. We dedicate this study to our landlady Lina Summermatter (1926-2010)—in loving memory, may you rest in peace.

\section{References}

Bleuler RM (1986) Jahrringanalysen von Lärchen in Gletschervorfeldern. Diploma thesis, Geographical Institute, University of Zürich

Burga CA (1999) Vegetation development on the glacial forefield morteratsch (Switzerland). Appl Veg Sci 2:17-24

Burnham KP, Anderson DR (2002) Model selection and multimodel inference: a practical-theoretic approach. Springer, New York

Crawley MJ (2007) The R book. Wiley, Chichester

Cunningham CA, Zimmerman NE, Stoeckli V, Bugmann H (2006) Growth response of Norway spruce saplings to artificial browsing, black snow mold, and ground vegetation in two forest gaps in the Swiss Alps. Can J For Res 36:2782-2796

del Moral R (1999) Plant succession on pummice at Mount St Helens, Washington. Am Midl Nat 141:101-104

del Moral R, Ellis EE (2004) Gradients in compositional variation on lahars, Mount St. Helens, Washington, USA. Plant Ecol 175:273-286

Desloges JR, Ryder JM (1990) Neoglacial history of the Coast Mountains near Bella Coola, British Columbia. Can J Earth Sci 27:281-290

Ellenberg H (1988) Vegetation ecology of central Europe. Cambridge University Press, New York

Erismann TH, Abele G (2001) Dynamics of rockslides and rockfalls. Springer, Berlin

Garbarino M, Lingua E, Nagel TA, Godone D, Motta R (2010) Patterns of larch establishment following deglaciation of Ventina glacier, Central Italian Alps. For Ecol Manag 259:583-590

Hoffmann S, Schweingruber FH (2002) Light shortage as a modifying factor for growth dynamics and wood anatomy in young deciduous trees. IAWA J 23:121-141

Huggel C, Salzmann N, Allen S, Caplan-Auerbach J, Fischer L, Haeberli W, Larsen C, Schneider D, Wessels R (2010) Recent and future warm extreme events and high-mountain slope failures. Philos Trans Roy Soc A 368:2435-2459

Lewis D, Smith DJ (2004) Little Ice Age glacial activity in Strathcona Provincial Park, Vancouver Island, British Columbia, Canada. Can J Earth Sci 41:285-297

Lindig-Cisneros R, Galindo-Vallejo S, Lara-Cabrera S (2006) Vegetation on tephra deposits 50 years after the end of the eruption of the Paricutín Volcano, Mexico. Southwest Nat 51:455-461

Masiokas MH, Luckman BH, Villalba R, Ripalta A, Rabassa J (2010) Little Ice Age fluctuations of Glaciar Rio Manso in the north Patagonian Andes of Argentina. Quat Res 73:96-106

McCarthy DP, Luckman BH (1993) Estimating ecesis for treering dating of moraines - a comparative study from the Canadian Cordillera. Arct Alp Res 25:63-68

Munoz-Salinas E, Manea VC, Palacios D, Castillo-Rodriguez M (2007) Estimation of lahar flow velocity on Popocatépetl volcano (Mexico). Geomorphology 92:91-99 
Pierson TC (2007) Dating young geomorphic surfaces using age of colonizing Douglas fir in southwestern Washington and northwestern Oregon, USA. Earth Surf Process Landf 32:811-831

Pinheiro JC, Bates DM (2000) Mixed-effects models in S and S-Plus. Springer, New York

Piotti A, Leonardi S, Piovani P, Scalfi M, Menozzi P (2009) Spruce colonization at treeline: where do those seeds come from? Heredity 103:136-145

Porter SC, Orombelli G (1980) Catastrophic rockfall of September 12, 1717 on the Italian flanc of the Mont Blanc massif. Zeitschrift für Geomorphologie 24:200-219

Schindler C, Cuenod Y, Eisenlohr T, Joris C-L (1993) Die Ereignisse vom 18. April und 9. Mai 1991 bei Randa (VS) ein atypischer Bergsturz in Raten. Eclogae Geologicae Helveticae 86:643-665

Shroder J Jr, Marston R, Stoffel M (2012) Treatise on geomorphology: mountain and hillslope geomorphology. Academic Press, San Diego, vol. 7, in press
Stauffer HB (2008) Contemporary Bayesian and Frequentist statistical research methods for natural resource scientists. Wiley, Chichester

Stoffel M, Lièvre I, Monbaron M, Perret S (2005) Seasonal timing of rockfall activity on a forested slope at Täschgufer (Swiss Alps) - a dendrochronological approach. Zeitschrift für Geomorphologie 49:89-106

Venables WN, Ripley BD (2002) Modern applied statistics with S. Springer, New York

Walker LR, Zarin D, Fetcher N, Myster R, Johnson A (1996) Ecosystem development and plant succession on landslides in the Caribbean. Biotropica 28:566-576

Wilson V. 1966. Plant colonization on part of the Hope landslide. Master thesis, Department of Geography, Simon Fraser University 